\title{
Nachruf Dipl. Ing. Alfred Weidner
}

\section{B. Hribernik}

\author{
ASMET, Leoben, Österreich
}

Online publiziert 14. Februar 2019

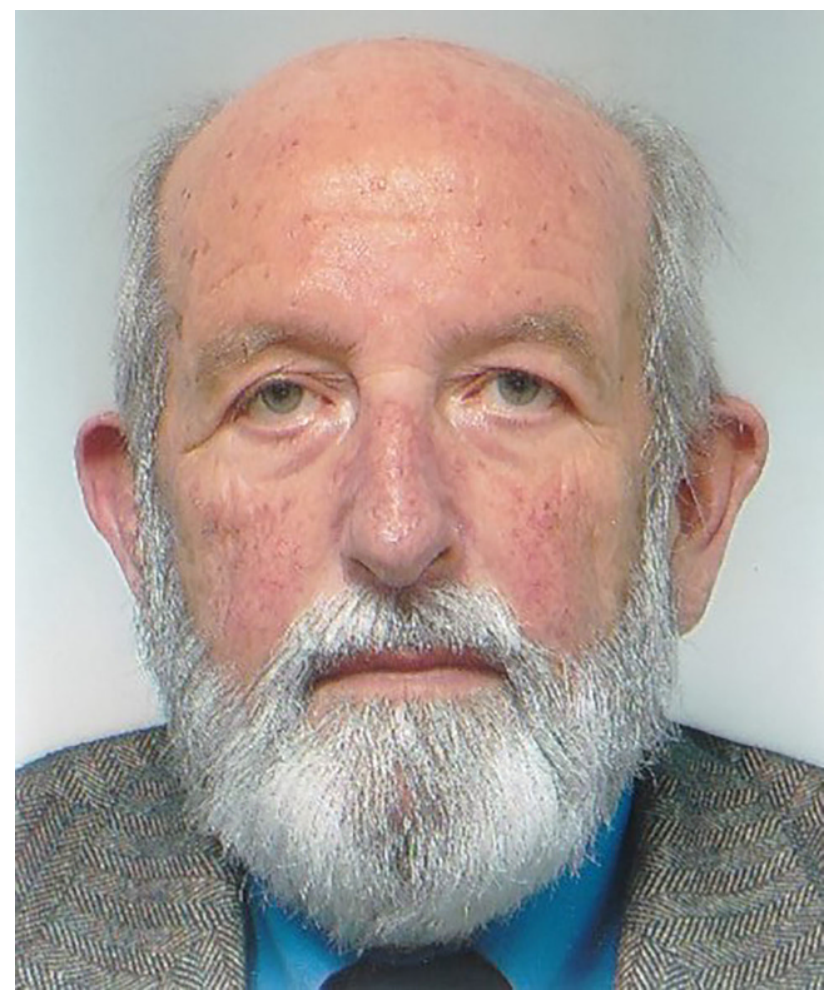

Dipl. Ing. Alfred Weidner

Am 22. Dezember 2018 starb Dipl. Ing. Alfred Weidner (1931-2018) im Landeskrankenhaus Villach.

Unsere aufrichtige Anteilnahme gilt seiner Frau Angelika und seinen Verwandten.

Alfred Weidner hat das Studium Hüttenwesen an der Montanistischen Hochschule Leoben mit Auszeichnung absolviert.

\section{Dr. B. Hribernik ( $\triangle)$ \\ ASMET, \\ Leoben, Österreich \\ bruno.hribernik@asmet.at}

Über Jahre war er ein hilfsbereiter und stets zuvorkommender Kollege und Führungskraft in Radenthein, wo er im Jahre 1957 bei der Österreichisch-Amerikanischen Magnesit AG heute RHIMagnesita als Reiseingenieur begann. Sehr rasch wurde er zu einem anerkannten Fachmann nicht nur im Feuerfestbereich und in der Metallurgie, sondern auch bei den Kunden weltweit.

Zu seinem Aufgabenbereich gehörten neben Europa, und hier insbesondere Skandinavien, Portugal und Spanien, die Länder im südlichen Afrika, Australien und auch Neukaledonien. Überall hatte er enge geschäftliche Kontakte aufgebaut und war ein gern gesehener Besucher und Fachmann. In Folge wurde er zum Oberingenieur befördert, und ganz besonders sein Fachwissen im Nichteisenbereich war sehr gefragt.

Kunden wie Outokumpo OY in Finnland, Mount Isa in Australien oder die Stahlwerke/Nichteisenwerke in Schweden, Portugal, Spanien, Sambia, Zimbabwe, Namibia und Südafrika gehörten zu den wichtigsten Abnehmern der Feuerfestprodukte, was beinahe ausschließlich auf sein Wirken und seine Beratung zurückzuführen war.

So hat Roy Edwards, der langjährige Vertreter für die Länder im südlichen Afrika, geschrieben: „We are very saddended at the passing of Alfred. What a dear and wonderful friend and business associate. Many miles spent on dirt roads and in far away places, but a great adventure. Condolences to Angelica, family and friends".

In den 80er-Jahren des vorigen Jahrhunderts wurde Alfred Weidner dann zum Leiter des Technischen Büros (RTB), einer Schlüsselabteilung, ernannt. Er war ein stets umsichtiger Chef, der fast zu allen Fragen eine Antwort wusste und große Anerkennung bei seinen Mitarbeitern und weltweit erwarb. Die letzten Jahre seiner beruflichen Tätigkeit verbrachte er im Bereich strategisches Marketing und war direkt der Konzernleitung unterstellt.

Mit ihm geht eine Ära hervorragenden Ingenieurwesens am Sektor feuerfeste Materialien sowie Metallurgie vorüber, und wir werden ihn in allen Belangen sehr vermissen.

Wir sind sehr froh, dass wir Alfred mit all seinen Talenten kennengelernt haben, und sind dankbar für die vielen schönen gemeinsamen Stunden. Seine Freundschaft, Hilfs- 
bereitschaft und guten Ratschläge werden uns fehlen. Er hinterlässt eine große Lücke, die sehr schwer zu schließen sein wird. Wir alle werden Alfred Weidner aufrichtig vermissen und ihm ein würdiges Andenken wahren.

Glückauf für deine letzte Schicht!

Mario G. de Piero, Bruno Hribernik 